\title{
Changes in Plasma Androgen Levels and Testicular Histology with Descent of the Testis in the Dog
}

\author{
Eiichi KAWAKAMI, Yoichi YAMADA, Toshihiko TSUTSUI, Akira OGASA, and Makoto YAMAUCHI \\ Department of Reproduction, Nippon Veterinary and Animal Science University, 1-7-1 Kyonan-cho, Musashino-shi, Tokyo 180, Japan
}

(Received 14 April 1993/Accepted 14 July 1993)

ABSTRACT. Levels of 4-androstenedione (A), $5 \alpha$-dihydrotestosterone (DHT) and testosterone (T) in plasma collected from the heart or the jugular vein were measured in 61 male fetal dogs at between 38 and 60 days of gestation and 55 male neonatal dogs at between 0 and 50 days after birth. Testicular descent and histology were investigated after euthanasia of the fetuses and neonates. Although the testis still lay on the caudal ridge of the kidney in the 38- and 40-day-old fetuses, the gonad had slightly migrated from the kidney by 42 days of gestation. The testis approached the internal inguinal ring at Day 0 after birth and had passed through the inguinal canal at Day 5 after birth. The inguinal passage was the active phase of testicular descent. Both testes were drawn into the scrotum after 35 days of age. The number of gonocytes in the seminiferous cords had increased in the 58-day-old fetus, and Leydig cells in the stroma had become obvious because of morphological development and the formation of cell clumps. Plasma A levels in the male fetuses decreased temporarily after birth and plasma DHT increased provisionally at 54 and 58 days of gestation. Plasma T levels in the male neonates increased markedly after birth. These findings suggest that testicular descent in the dog fetus is accelerated by the DHT and T secretory function of the Leydig cells which increased after 54 days of gestation.-KEY wORDs: androgen, canine, histology, testicular descent.

J. Vet. Med. Sci. 55(6): 931-935, 1993

In most mammals, the testis originates on the caudal ridge of the kidney in the abdominal cavity during the fetal period, then passes through the inguinal canal and descends into the scrotal cavity [16]. The mechanisms of this process, however, are not completely understood. Testicular descent is usually said to be achieved as a result of tension exerted by the gubernaculum and the vaginal process. The former is a thick, fibrous, white ligament which develops from mesenchyme, while the latter consists of a pocket-like projection extending from the external inguinal ring toward the scrotum and enclosing the gubernaculum $[2,6,18]$. It has been reported that Müllerian inhibitory hormone [12, 14], an unidentified non-androgenic factor secreted by the testis $[5,17]$, and intra-abdominal pressure increased by development of the internal organs [7-10] play an important role in the descent of the testis. However, it is generally believed that androgens secreted by the fetal testis induce testicular descent $[5,8,9,11,15]$. The time of descent varies according to the species [10], and the time in the dog is known to be much later than in other animals $[4,10,18]$. Baumans et al. [4] reported observing complete descent of the testis into its final position in the scrotal cavity at Day 35 after birth and finding that testosterone (T) promotes gubernacular outgrowth [5] in the dog. Gier and Marrion [10] observed seminiferous cords, later as seminiferous tubules and gonocytes, within the cords in the gonads of 34-day-old fetuses. However, there have been no comprehensive reports on changes in plasma levels of 4androstenedione (A), $5 \alpha$-dihydrotestosterone (DHT) and $\mathrm{T}$, or changes in testicular histology accompanying descent of the testis in the dog. In the present study, the process of normal testicular descent was observed closely, and changes in plasma levels of A, DHT and T and histological changes in the testis were investigated in relation to testicular descent in fetal and neonatal dogs.

\section{MATERIALS AND METHODS}

Cesarean section was performed under halothane inhalation anesthesia on 33 pregnant mongrel bitches and 2 beagle bitches having a body weight of about $10 \mathrm{~kg}$ before pregnancy. Sixty-one male fetuses between 38 and 60 days of gestation were used at 2 or 3 days intervals. In addition, 55 male neonates born of 36 mongrel and 20 beagle bitches were used between Day 0 (62-65 days of gestation) and Day 50 after birth at 2, 3, 5 and 10 days intervals. Specimens were sampled from 3-11 male fetuses or neonates at each day of age, and the crown-rump length and body weight of the male fetuses and neonates were measured. Blood for plasma hormone assay was collected from the hearts of 26 male fetuses and from the jugular veins of 24 male neonates. Then all of the male fetuses and neonates were sacrificed by intravenous injection of a lethal dose of pentobarbital sodium.

The distance (A) between the caudal ridge of the kidney and the scrotal floor and the distance (a) between the kidney and the caudal ridge of the testis were measured, and $\mathrm{a} / \mathrm{A} \times 100$ was taken as the degree $(\%)$ of testicular descent. The distance (B) between the external inguinal ring and the scrotal floor and the distance (b) between the inguinal ring and the tip of the vaginal process were measured, and $\mathrm{b} / \mathrm{B} \times 100$ was taken as the degree $(\%)$ of extension of the vaginal process.

After orchiectomy, each testis was weighted and fixed in Bouin's fluid. Testicular tissue was cut into sections $3 \mu \mathrm{m}$ thick and stained with hematoxylin and eosin. The number of gonocytes in the seminiferous cords and that in the cords in the cross-section of middle position of the testis were counted. 
Plasma levels of A, DHT and T were determined by radioimmunoassay as described previously [13]. Androgens were extracted with anhydrous ether and A, DHT and T were separated by column chromatography (Sephadex LH-20). The rabbit antisera to A-3carboxymethyl-oxime-BSA, DHT-11-succinate-BSA and T-11-succinate-BSA were used. The sensitivities of these assays were all $20 \mathrm{pg} /$ tube. Intra- and inter-assay coefficients of variation were A: 9.0 and $10.5 \%$, DHT: 11.7 and $7.8 \%$, and $\mathrm{T}: 3.0$ and $7.0 \%$, respectively.

RESULTS

Body weight, crown-rump length and testicular weight: Changes in mean $( \pm$ S.E.) body weight, crown-rump length and testicular weight accompaying the growth of male fetuses and neonates are shown in Fig. 1. Since the weights of the right and the left testes were almost exactly the same, the weight of the left is reported. The weight of the body and the testis increased markedly between Days 10 and 40 after birth. Crown-rump length increased linearly throughout the experimental period.

Degree of testicular descent and extension of the vaginal process: There were no differences in the degrees of testicular descent and extension of the vaginal process on the right and the left. Hence, the mean ( \pm S.E.) values for the left alone are shown in Fig. 2. The degrees of testicular descent and extension of vaginal process increased markedly as outgrowth of the fetuses and the neonates.

Although the testis still lay on the caudal ridge of the kidney in the 38- and 40-day-old fetuses, the tip of the vaginal process had already reached one-third of the

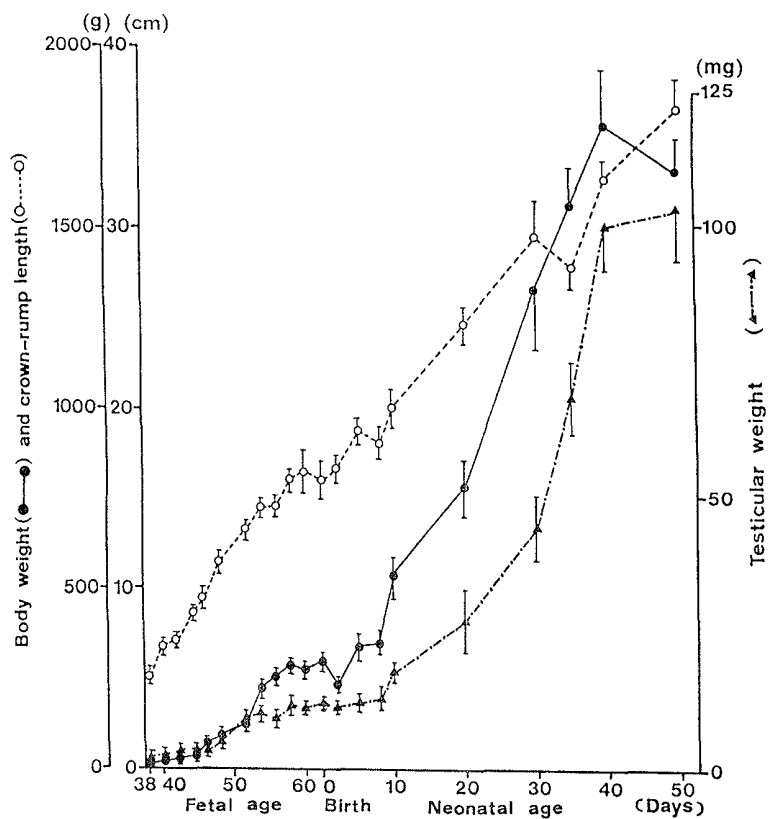

Fig. 1. Changes in mean $( \pm$ S.E. $)$ body weight, crown-rump length and testicular weight ${ }^{\text {a) }}$ accompanying growth in 3-11 male canine fetuses and neonates at each day of age. a) The weight of the left testis.

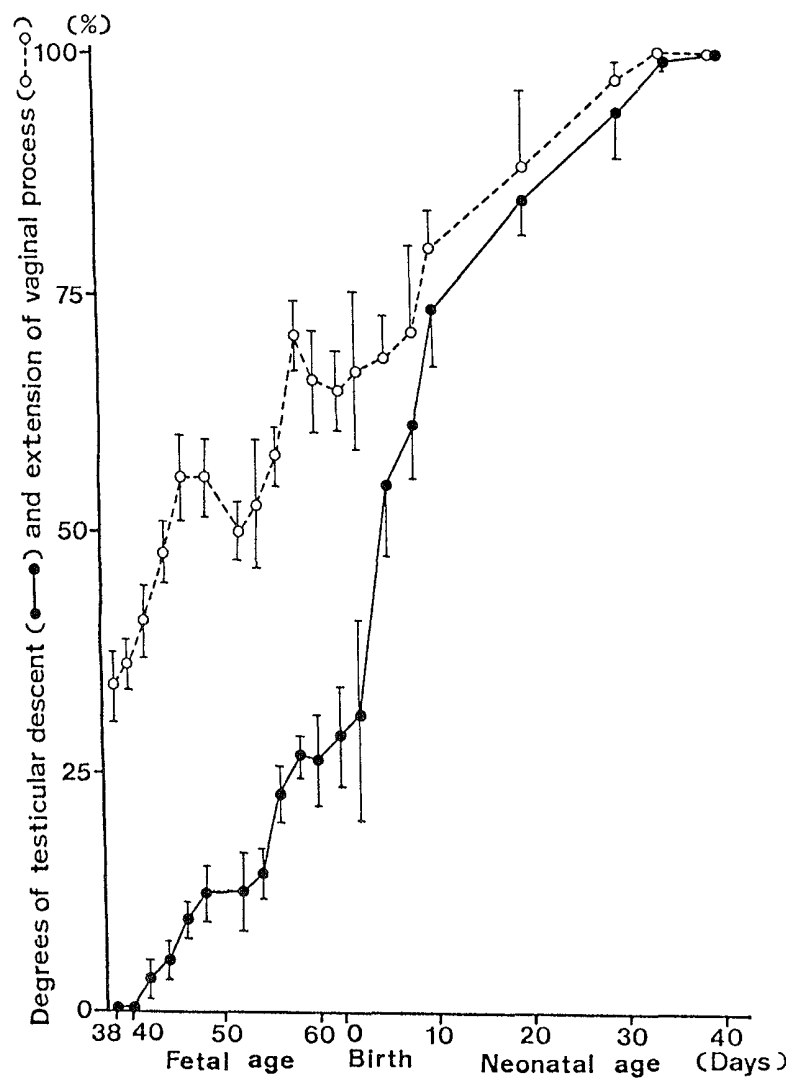

Fig. 2. Changes in mean $( \pm$ S.E. $)$ degrees of testicular descent $^{\text {a) }}$ and extension of the vaginal process ${ }^{\text {b) }}$ in 3-11 male canine fetuses and neonates at each day of age. a) Ratio of distance between the kidney and the testis to distance between the kidney and the scrotal floor. b) Ratio of distance between the external inguinal ring and the tip of the vaginal process to distance between the inguinal ring and the scrotal floor.

distance from the external inguinal ring to the scrotal floor (Fig. 3-a). The testis had migrated slightly away from the kidney at 42 days of gestation and was located about $5 \mathrm{~mm}$ from the internal inguinal ring in the abdominal cavity at 60 days (Fig. 3-b). At Day 0 after birth the canine testis has not yet passed into the inguinal canal. However, inguinal passage had been completed in 6 of 9 neonatal dogs at Day 5 after birth (Fig. 3-c), and the degree of testicular descent increased markedly at this time. At Day 30 after birth the position of both the right and the left testes was extremely close to the scrotum, and the vaginal process has reached the scrotal floor (Fig. 3-d). Complete descent of the testis into the scrotal cavity was observed at Days 35 and 40 after birth in all 10 dogs.

Histological findings in the testis: Seminiferous cords were observed in the testicular parenchyma and supporting cells were located along the basement membrane of the cord in the 38-day-old fetus (Fig. 4-a). Only one or two gonocytes were seen in the central position of a few seminiferous cords at that time.

Leydig cells became apparent in the stroma because of morphological development and the formation of cell 

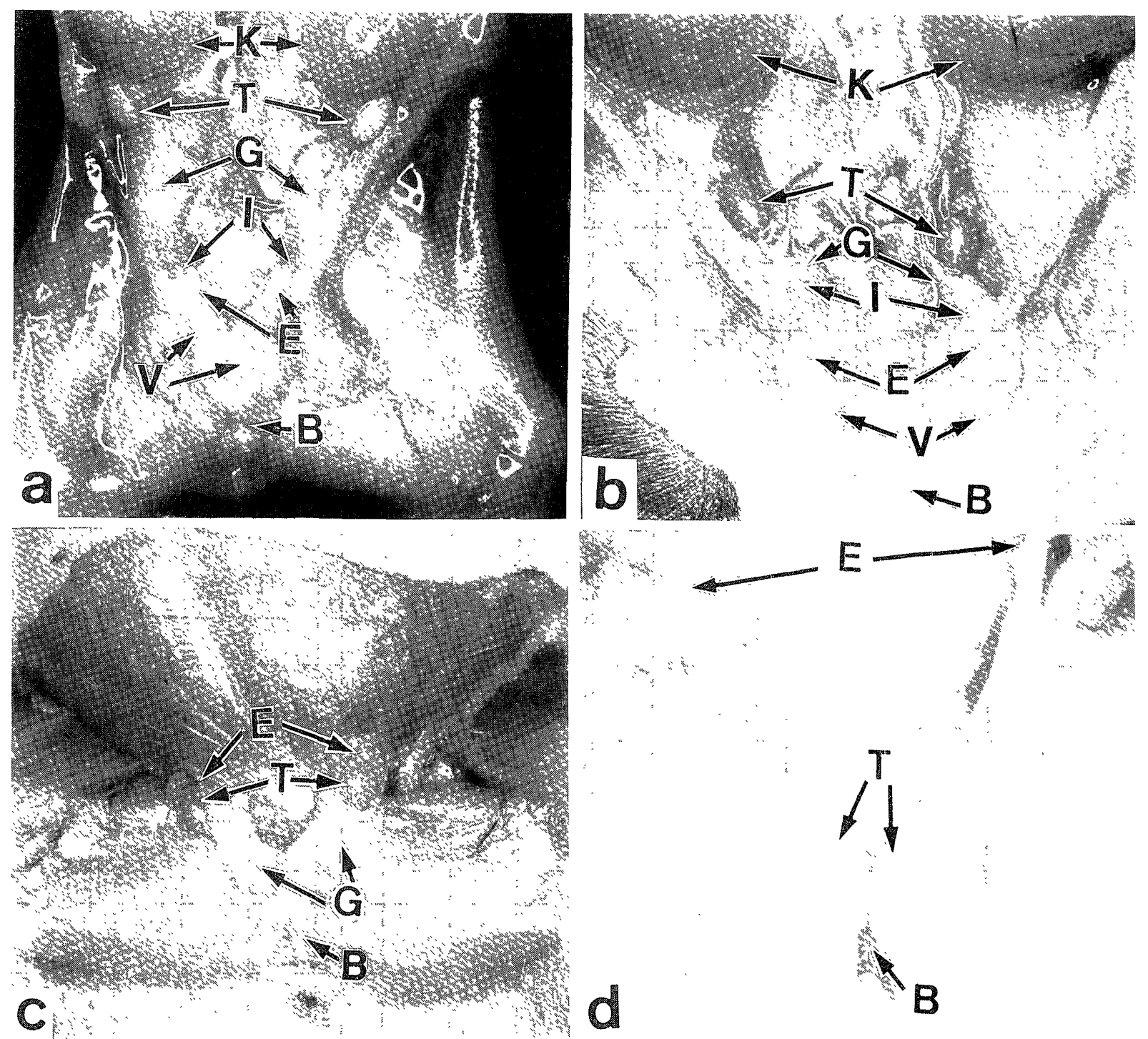

Fig. 3. Descent of the testis in the dog. B, bottom of the scrotal cavity; E, external inguinal ring; G, gubernaculum; I, internal inguinal ring; $\mathrm{K}$, kidney; $\mathrm{T}$, testis; $\mathrm{V}$, vaginal process. a: 38-day-old fetus. The testes still lie on the caudal ridge of the kidney. $\mathrm{b}$ : 60-day-old fetus. The testes are located near the internal inguinal ring. c: 5 -day-old neonate. The vaginal process has been removed, and the gubernaculum is exposed. Both testes have already passed through the inguinal canal. d: 30-day-old neonate. The vaginal process has been removed. The testes are located close to the scrotum or have reached it.

clumps in the 54-and 58-day-old fetuses. A few gonocytes were seen in most of the seminiferous cords in the 58-day-old fetus (Fig. 4-b), and the number of gonocytes in the seminiferous cords in the cross-section of the middle position had obviously increased at Day 5 after birth (Figs. 4-c and 5). Moreover, the number of seminiferous cords in the testicular cross-section had increased markedly with the increase in testicular size at Day 30 after birth (Figs. 4-d and 5).

Plasma A, DHT and T levels: Changes in the mean ( \pm S.E.) levels of plasma $A, D H T$ and $T$ accompanying growth in the male fetuses and neonates are shown in Fig. 6. Plasma DHT levels, in particular, had increased at 54 and 58 days of gestation. Although the plasma DHT level remained low after 60 days of gestation, the plasma $T$ level in the neonates increased after 5 days of age and became high at 30 days of age.

\section{DISCUSSION}

It has been reported that intra-abdominal pressure increased by the development of the internal organs in the fetus induces extension of the vaginal process and descent of the testis $[7,8,10]$. In the present study, the degree of testicular descent accelerated in association with the marked increase in body and testis weight after birth. Baumans et al. [4] observed that the testis of the dog completed its passage through the inguinal canal on Day 4 after birth and reached its scrotal location at Day 35, and we observed the same findings. 


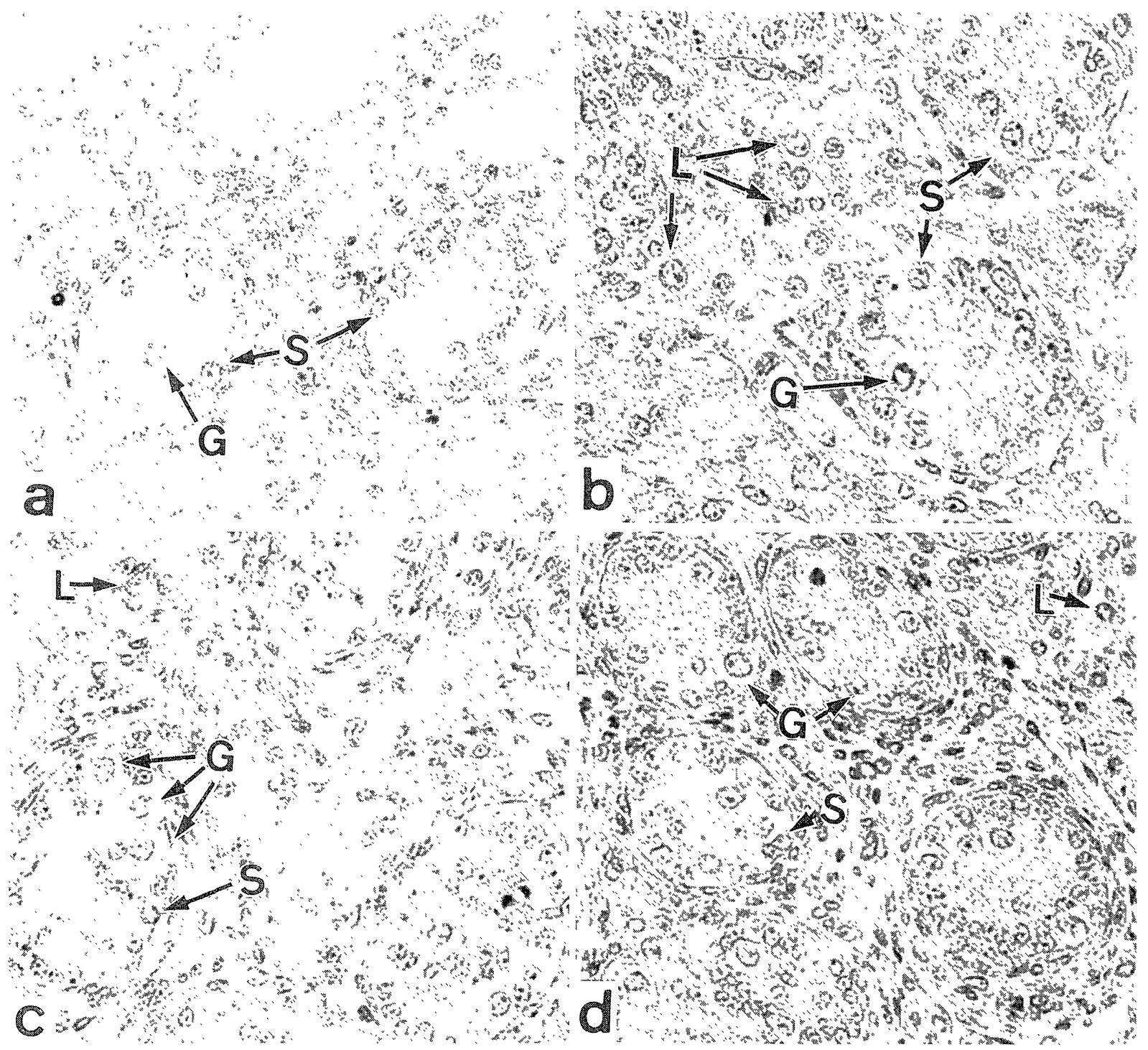

Fig. 4. Testicular histology of dog fetuses and neonates. H.E stain, $\times 200$. G, gonocyte; L, Leydig cell; S, Sertoli cell. a: 38-day-old fetus. Not only supporting cells but also gonocytes are observed in some seminiferous cords. b: 58-day-old fetus. Leydig cells have become obvious because of morphological development and the formation of the cell clumps in the stroma. c: 5-day-old neonate. The number of gonocytes in the seminiferous cords has increased. d: 30-day-old neonate. The number of seminiferous cords in the testicular cross-section has increased markedly.

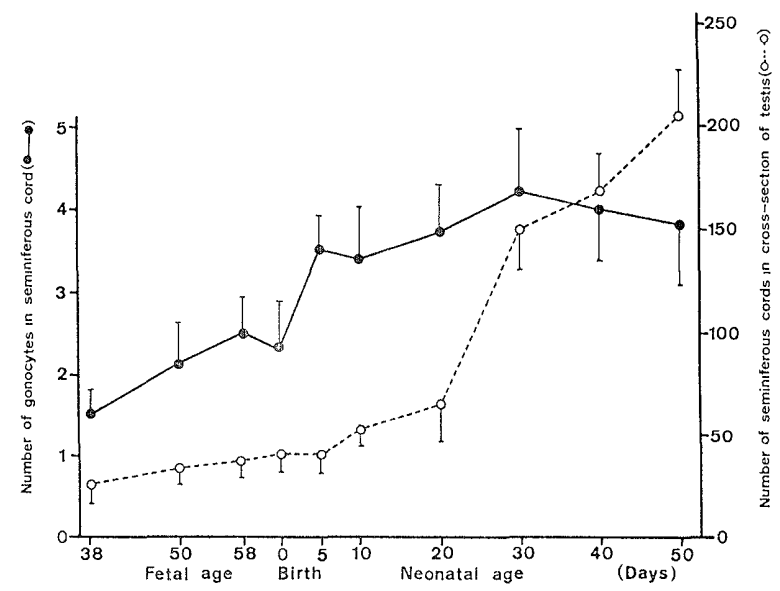

Fig. 5. Changes in mean $( \pm$ S.E. $)$ number of gonocytes in the seminiferous cords and that of the cords in the cross-section of middle position of the testis in 3-11 male canine fetuses and neonates at each day of age. 


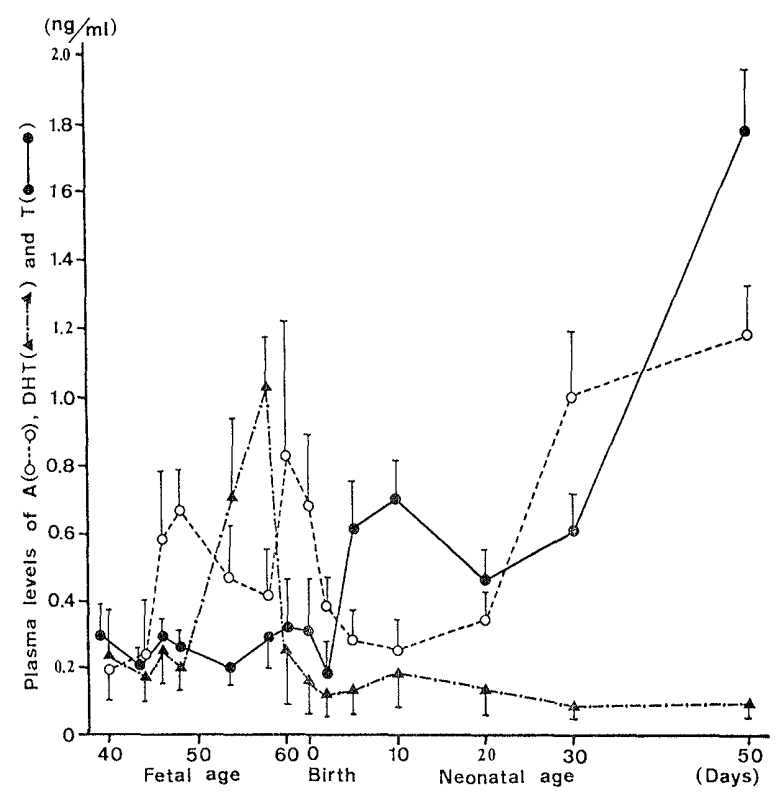

Fig. 6. Changes in mean $( \pm$ S.E. $)$ levels of plasma ${ }^{\text {a) }}$ 4androstenedione (A), $5 \alpha$-dihydrotestosterone (DHT) and testosterone $(\mathrm{T})$ in 3-11 male canine fetuses and neonates at each day of age. a) Plasma was collected from the hearts of the fetuses and from the jugular veins of the neonates.

A marked increase in the degree of testicular descent was noted during passage through the inguinal canal on Day 5 after birth. Therefore passage through the inguinal canal appears to be most important for testicular descent.

The morphology of the Leydig cells in the testis of the dog fetus came to resemble that of the adult dog and clumps of cells were first observed in the stroma at 54 and 58 days of gestation. Thereafter, the number of gonocytes in the seminiferous cords increased. In view of these results, the transient rise in plasma DHT in the 54- and 58-day-old male fetuses and the marked rise in plasma $\mathrm{T}$ in the neonates is believed to have played a major role in the histological changes in the testis. It has been reported that testicular descent depends not only on T but also on DHT, which is synthesized by the testis $[8,12,14,15]$. Baumans et al. [3] did not find any marked changes in plasma $\mathrm{T}$ levels in the male dog between 53 days of gestation and 30 days after birth. However, they [5] concluded that $T$ induces outgrowth of the gubernaculum in the dog. The results of this study indicate that remarkable descent of the testis occurs after birth, associated with increases in the plasma concentrations of DHT and T secreted by Leydig cells in the fetal and neonatal testis after 54 days of gestation.

REFERENCES

1. Andersen, A. C. and Simpson, M. E. 1973. Differentiation of the testis and ovary. pp.28-29. In: The ovary and
Reproductive Cycle of the Dog (Beagle). Geron-X, Inc., Los Altos, California.

2. Backhouse, K. M. and Butler, H. 1960. The gubernaculum testis of the pig. J. Anat. 94: 107-123.

3. Baumans, V., Dieleman, S. J., Wouterse, H. S., van Tol, L., Dijkstra, G., and Wensing, C, J. G. 1985. Testosterone secretion during gubernacular development and testicular descent in the dog. J. Reprod. Fertil. 73: 21-25.

4. Baumans, V., Dijkstra, G., and Wensing, C. J. G. 1981. Testicular descent in the dog. Zentralbl. Veterinaermed., $C$ 10: $97-110$.

5. Baumans, V., Dijkstra, G., and Wensing, C. J. G. 1983. The role of a non-androgenic testicular factor in the process of testicular descent in the dog. Int. J. Androl. 6: 541-552.

6. Bergh, A., Helander, H. F., and Wahlqvist, L. 1978. Studies on factors governing testicular descent in the rat: Particularly the role of gubernaculum testis. Int. J. Androl. 1: 342-356.

7. Bergin, W. C., Gier, H. T., Marion, G. B., and Coffman, J. R. 1970. A developmental concept of equine cryptorchism. Biol. Reprod. 3: 82-92.

8. Elder, J. S., Isaacs, J. T., and Walsh, P. C. 1982. Androgenic sensitivity of the gubernaculum testis: Evidence for hormonal/mechanical interactions in testicular descent. J. Urol. 127: 170-176.

9. Frey, H. L., Peng, S., and Rajfer, J. 1983. Synergy of abdominal pressure and androgens in testicular descent. Biol, Reprod. 29: 1233-1239.

10. Gier, H. T. and Marrion, G. B. 1969. Development of mammalian testes and genital ducts. Biol Reprod. (Suppl.) 1: $1-23$.

11. Husmann, D. A. and McPhaul, M. J. 1992. Reversal of flutamide-induced cryptorchidism by prenatal time-specific androgens. Endocrinology 131: 1711-1715.

12. Hutson, J. M. 1985. A biphasic model for the hormonal control of testicular descent. Lancet 2: 419-421.

13. Kawakami, E., Tsutsui, T., Yamada, Y, Ogasa, A., and Yamauchi, M. 1987. Spermatogenesis and peripheral and spermatic venous plasma androgen levels in unilateral crytorchid dogs. Jpn. J. Vet. Sci. 49: 349-356.

14. Radhakrishnan, J., Morikawa, Y., Donahoe, P. K., and Hendren, W. H. 1979. Observations on the gubernaculum during descent of the testis. Invest. Urol. 16: 365-368.

15. Rajfer, J. and Walsh, P. C. 1977. Hormonal regulation of testicular descent: Experimental and clinical observations. J. Urol. 118: 985-990.

16. Setchell, B. P. 1978. Testicular migration. pp. 33-36. In: The Mammalian Testis (Finn. C. A. ed.), Paul Elek, London.

17. van Vlissingen, J. M. F., van Zoelen, E. J. J., Ursem, P. J. F., and Wensing, C. J. G. 1988. In vitro model of the first phase of testicular descent:Identification of a low molecular weight factor from fetal testis involved in proliferation of gubernaculum testis cells and distinct from specified polypetide growth factors and fetal gonadal hormones. Endocrinology 123: 2868-2877.

18. Wensing, C. J. G 1968. Testicular descent in some domestic mammals. I. Anatomical aspect of testicular descent. Proc. Kon. Akad. Wetensch. C71: 423-434. 